\title{
Psychological debriefing (PD) of trauma: a proposed model for Africa
}

\author{
EL VAN DYK AND GAJ VAN DYK"
}

\begin{abstract}
Africa is a continent with severe trauma. Traumatic events include experiences of child soldiers, people living in war and conflict zones, and people struggling with the HIV/AIDS pandemic. These events cause high levels of trauma. The trauma causes psychological disorders like post traumatic stress disorder, acute stress disorder and combat stress reaction, specific in the military environment.

This article focuses on a better understanding of the implications of trauma for military people and civilians. It discusses the different theories and models of psychological debriefing. Lastly the article discusses psychological debriefing models for military forces and the civilian population to prevent severe psychopathology after traumatic incidents in Africa.
\end{abstract}

Keywords: Psychological debriefing, community health, social work, model for Africa.

Disciplines: Community health, social work, psychology, education, nursing

\section{Introduction}

Africa is a continent with severe trauma. According to the Human Development Report (2005), $40 \%$ of the world's conflict is in Africa. Notably, child soldiers have been used throughout Africa. In Uganda up to 2000 women and children were captured by the Lord's Resistance Army (LRA). The LRA was responsible for the killing, torture, rape, mutilation and abduction of thousands of adults and children until late 2005. On the other hand the United People's Defence Force (UPDF) used child soldiers to gather intelligence from the LRA. In Sudan thousands of child soldiers were recruited and used by armed forces, government backed militias and armed opposition groups. The youngest was 9 and the average age was 16 years old. In Zimbabwe, the National Youth Training Programme for people between 10 and 30 years old, was used up until 2007 to train people for political intimidation, attacks on the opposition, forced displacement, killings, torture, rape and the destruction of property (The Coalition to Stop the Use of Child Soldiers, 2008).

Department of Industrial Psychology, Faculty of Military Science, Stellenbosch University, Saldanha, Email: vdyk@ma2.sun.ac.za 
In Africa there are 2,2 million refugees. New armed conflict in Central African Republic, Chad, Democratic Republic of Congo (DRC), Somalia and Sudan led to refugee outflows into Kenya (25 000), Cameroon (25 000), Sudan (22 500) and Uganda (9400) (The UN Refugee Agency, 2007).

It could be argued that sexualised violence perpetrated by soldiers in wartime does more than harm the physical and mental health of women. Many victims have struggled with lasting consequences both physical and psychological. In war, rape is a deliberate strategy. After mass rapes of women and girls, perpetrators can share a feeling of omnipotence, and leaders may want exactly that to happen as a way of boosting cohesion in the troops, while traumatising the enemy. It can also contribute to the spreading of the HIV/AIDS pandemic in Africa: SubSaharan Africa remains the region most affected by AIDS, with more than two thirds $(68 \%)$ of all people infected with HIV living there. Women are disproportionately affected, representing $61 \%$ of people living with HIV in the region (UNAIDS, 2007).

In the military environment in Africa other traumatic stressors are involved. The well known wars in Burundi, DRC and Sudan for example caused high levels of trauma for the soldiers involved. Dhladhla (2008, p 68) did research on ex-combatants and wrote: "participation in war or armed conflict is a recognised pathogenic stressor which often results in psychological dysfunction", if the trauma is not treated. Bruwer and Van Dyk (2005) wrote that in peacekeeping operations in Africa, soldiers often experienced the following stressors as traumatic: separation from the family, isolation and frustration during the operation, harsh environmental conditions, child soldiers and causalities of the population like pregnant women. These are some statistics illustrating the extent to which trauma in Africa has the potential to destroy the mental health of people, their future, relationships and reason for existence.

This article will look at Psychological Debriefing (PD), as an intervention, after a traumatic event or a traumatic phase of life with the aim of preventing psychological complications, healing pain and creating future orientation. Trauma and some common consequences of trauma will be discussed so that one can understand why PD can play an important role after traumatic events. This paper will also focus on the different models of PD, the role of PD during military operations, as well as in traumatic circumstances in countries in Africa. A proposed PD model for military forces in Africa, as well as for the civilian populations will be discussed. This paper will contribute to disciplines like community health, military science, psychology and social work on knowledge and skills.

\section{What is trauma}

In order to understand PD one must first understand trauma. According to Perry (2006, p.1), "trauma is a psychologically distressing event that is outside the range of usual human experience". He continues to say that trauma often involves a sense of fear, terror and helplessness, and that trauma is an experience that induces an abnormally intense and prolonged stress response (Perry, 2006). In such circumstances it can destroy the health levels of a community, for example, after a disaster.

Trauma can also be seen as the influx of violent and urgent events which exceeds the defensive capacity of the person, such that the person can not master these events through normal adjustment processes (Crocq, \& Crocq, 1987). Trauma is most often the result of a critical incident (rape), series of incidents (disasters) or a situation like war. 
Lewis (2001) writes a critical incident is described as any unplanned, unexpected or unpleasant situation faced that causes individuals to experience unusually strong emotional reactions and which have the potential to interfere with their ability to function either immediately or later. War is an ongoing destructive process, where the population and soldiers experience trauma, losses, helplessness, feel out of control, struggle with feelings of anger, hate, resentment and sadness. The underlying assumption of PD is that reactions due to trauma are normal expected reactions being experienced by a normal person in response to an abnormally challenging situation (Lewis, 2001).

\section{Consequences of trauma}

Trauma affects every part of a person's being - their thoughts, emotions, behaviour and physical reactions. Trauma also refers to overwhelming, uncontrollable experiences that psychologically impact on victims by creating in them feelings of helplessness, vulnerability, loss of safety and loss of control. These traumatic results can result in psychological disorders such as 'Post Traumatic Stress Disorder', 'Acute Stress Disorder' and 'Combat Stress Reaction' in military operations.

\section{Post traumatic stress}

Prior to 1980 there was no formal diagnosis for Post Traumatic Stress Disorder (PTSD). People who showed symptomatic behaviour as a result of a traumatic event were described as having a character defect (Carll, 2007). PTSD was first recognised as a psychiatric disorder in the third edition of the American Psychiatric Association's Diagnostic and Statistical Manual of Mental Disorders (DSM-III) (McNally, Bryant, \& Ehlers, 2003).

PTSD is a psychiatric disorder that can occur in soldiers and other people who have experienced or witnessed life-threatening events such as natural disasters, terrorist incidents, war or violent personal assaults. People suffering from PTSD often re-live the experience through nightmares or flashbacks of the incident. They may also have difficulty sleeping and can feel detached from their environment. PTSD can lead to the development of other related disorders such as depression (American Psychiatric Association (APA), 2005).

People who suffer from a traumatic event may have a range of different reactions including anger, self-blame, fear and anxiety. The question, however, is what qualifies as a traumatic event? According to the DSM (APA, 2005), to qualify as being exposed to trauma, an individual no longer needs to be a direct victim. As long as the person is confronted with a situation that involves threat to the physical integrity of that person or others and experiences the emotions of fear, horror or helplessness, then the experience counts as exposure to a PTSD-qualifying stressor (APA, 2005). Usually, PTSD will appear within three months of the traumatic incident, but it may at times only appear later (Baumann, 1998).

According to Baumann (1998) factors that influence the vulnerability of the individual to the development of PTSD include the following:

- Psychological difficulties present before the traumatic event.

- The trauma is severe and/or persisting.

- The age of the person.

- Absence of a social support system. 
- Previous exposure to trauma.

- Lack of safety in their environment.

- The trauma was initiated by people rather than nature.

The more factors that are present, the more likely it will be that the person will be vulnerable to trauma. PTSD symptoms are grouped into three categories: 1) intrusion or the re-experiencing of the event, 2) avoidance of associated stimuli and emotional numbing and 3) hyperarousal (Baumann, 1998).

Intrusion is when people complain that memories of the traumatic incident come back to them unexpectedly. These flashbacks of the events intrude into their lives and cause discomfort. These sudden, vivid memories will normally be accompanied by strong painful emotions associated with the traumatic event. These flashbacks can sometimes be so strong that the person feels that he/she is experiencing the traumatic event all over again (APA, 2005).

Avoidance symptoms tend to affect relationships with others. The person may try to avoid close emotional ties with family, colleagues and friends. At first, the person may feel numb and only complete routine, mechanical activities. Then, when re-living the traumatic event, the individual may alternate between a flood of emotions caused by the flashbacks of the events and an inability to feel or express emotions at all. A person with PTSD may try to avoid situations that are reminders of the original traumatic event (Baumann, 1998).

PTSD can cause individuals to act as if they are constantly threatened by the trauma that caused their disorder. This hyperarousal can cause them to become suddenly irritable or explosive, even when unprovoked. They may have trouble concentrating or remembering current information and, because of terrifying nightmares, may develop insomnia. Many people with PTSD also attempt to rid themselves of painful flashbacks, loneliness and anxiety by abusing alcohol or other drugs to help them dull or forget the pain and trauma temporarily. This tendency can lead to further problems in their personal lives (Baumann, 1998).

\section{Acute stress disorder}

The definition of Acute Stress Disorder (ASD) requires that the individual has experienced or witnessed an event that has been threatening to either him/herself or another person and that the person's response to this event must involve fear, helplessness or horror (Bryant, \& Harvey, 2002). The symptom cluster that distinguishes ASD from PTSD is the emphasis on dissociative symptoms.

A person must display at least three of the following symptoms in order to satisfy the criteria: 1) a subjective sense of numbing or detachment, 2) reduced awareness of his/her surroundings, 3) derealisation, 4) depersonalisation and 5) dissociative amnesia (Bryant, \& Harvey, 2002). Numbing refers to a detachment from expected emotional reactions. The individual tends to show no emotions regarding the traumatic event. Reduced awareness of his/her surrounding refers to the person being less aware of what is happening around him/her during the traumatic event or immediately after it. Derealisation is when the person perceives his/her environment to be unreal or dreamlike. Depersonalisation refers to the sense that one's body is detached or a person is seeing himself or herself from another's perspective. Dissociative amnesia refers to the person's inability to recall specific parts of the traumatic event (Bryant, \& Harvey, 2002). 
The only other significant difference between ASD and PTSD is the time frame given for diagnosis. The time frame for ASD requires that the symptoms be present two days after the event and not persist for more than one month. Persons suffering from ASD will receive treatment much earlier due to this time period (Bryant, \& Harvey, 2002).

\section{Combat stress reaction}

Combat Stress Reaction (CSR) is also known as battle fatigue, shell shock and combat neurosis. Generally, CSR is characterised by a reduction in the person's capacity to function as a soldier and the subjective experience of overwhelming distress and inescapable anxiety (Freedy, \& Hobfoll, 1995). According to Noy (1987), CSR consists of three stages: 1) immediate, 2) acute and 3) chronic. The immediate stage is characterised by anxiety, hyperactivity and panic after, for example, an artillery bombardment. Intense emotional turmoil, in the form of rage, crying and terror or extreme unresponsiveness can be observed. These extreme reactions can start suddenly at a breaking point or they can gradually build up to a point. During this stage, it may still be possible to prevent the disorder with psychological debriefing from developing to the next stage. During the acute stage, the soldier may try to use defense mechanisms like repression, dissociation or denial.

PD alone will no longer be effective during this stage. The soldier will need more treatment then PD, which can include removal from the battlefield, sometimes hospitalised with medication and a more detailed long term treatment approach (Nathan, 2005). During the chronic phase functional efficiency is reduced and the soldier will suffer from exaggerated startle response, explosive anger, disruptive sleep and persistent battle dreams. This phase is very similar to PTSD and may persist indefinitely (Noy, 1987). Normally, the soldier also needs more than PD.

The principle indicators of CSR includes: 1) strong enough emotions that interfere with task accomplishments, 2) tension that is out of the control of the soldier and that does not decrease during times of relief, 3) distress that is significantly more intense than that of other soldiers that are experiencing the same conditions and 4) behaviour that is different to that of the soldier's normal behaviour (Freedy, \& Hobfoll, 1995). If this disorder is left untreated it can ultimately lead to the development of PTSD (Noy, 1987).

\section{Trauma experienced during military operations and disasters}

Although each war and each deployment is different, there are however some fundamental aspects that are the same. Freedy and Hobfoll (1995) discuss some dimensions of war-zone stress. The biggest stressor for any soldier is the possibility that he/she may lose his/her life or he/she may lose a close friend. Other stressors that can lead to PTSD and CSR include demands on physical and emotional resources, levels of combat exposure, witnessing abusive violence, participation in abusive violence and subjective or perceived threats.

Demands on emotional resources can take the form of threats of personal injury or engaging in hostile destructive activities whereas demands on physical resources can take the form of inadequate supply of food, water and shelter as well as physical exertion. Levels of combat exposure can take many forms for example being on the receiving end of a fire fight, firing a weapon at an enemy and being exposed to wounded, dying or dead people (Freedy, \& Hobfoll, 1995). 
During peacekeeping missions, soldiers are not often actively involved in fire fights and are exposed to situations where they witness the aftermath of brutal attacks on civilians or the attack itself and they are not allowed to intervene. This can create feelings of powerlessness and also contribute to PTSD and CSR (Freedy, \& Hobfoll, 1995).

During disasters in Africa like the flood in Mozambique, the drought in Ethiopia, bomb blasts in Uganda or with personal disasters like rape, communities or individuals can experience shock, overwhelmed by emotions, can feel traumatised and helpless without a vision for the future. Such a situation can destroy the community's health and can be characterised by the anxiety, depression, anger and conflict. This paper wants to empower community health workers, social workers, community leaders and psychologists to help with PD.

\section{Defining psychological debriefing}

PD has been defined as " $a$ brief, short-term intervention aimed at mitigating long-term distress and preventing the emergence of post traumatic stress" (Devilly, Gist, \& Cotton, 2006, p.318). PD has also been defined as a "planned structured group activity, organised to review in detail the facts, thoughts, impressions and reactions following a critical incident" (Dyregrov, 1997, p.589). PD is implemented within three days after a traumatic event and is predominantly done in terms of group interventions facilitated by trained peers or mental health professionals (Foy, Eriksson, \& Trice, 2001). PD is a single session, semi-structured crises intervention designed to reduce unwanted psychological problems following a traumatic event by promoting emotional processing through the ventilation and normalisation of reactions (Bisson, McFarlane, \& Rose, 2000). However, it must be made clear that PD is not psychotherapy or counselling, but only an intervention (Van Dyk, 2000).

\section{The aim of psychological debriefing}

PD aims to prevent the development of abnormal stress responses and tries to promote normal stress responses (Deahl, 2000). Furthermore, PD aims to prevent the after effects of trauma, such as PTSD and CSR, stimulate group cohesion, normalise reactions, accelerate normal recovery, stimulate emotional ventilation and promote a cognitive grip on the situation (Dyregrov, 1997). Van Dyk (1999) writes that after the emotions are debriefed it is most important to empower or better still, "ego-power" the victim. The ego represents the centre of our decisions, plans, actions and reactions. If the ego is developed, it is well able to deal with many difficult situations and master the future in a more competent way, instead of getting under severe pressure of anxiety. PD is also used as a screening function to determine whether or not a person who experienced trauma should be referred for treatment or not (Arendt, \& Elklit, 2001).

\section{A brief history of psyhological debriefing}

PD dates as far back as World War I. During this war, a model that was based on three principles, namely proximity, immediacy and expectancy (PIE) was utilised. The focus of this model was to treat soldiers close to the battlefield (proximity) as soon as possible (immediacy) with a strong prospect that they would return to the battlefield for active duty (expectancy). During World War II, Brigadier General Samuel Marshall was the chief historian of the US Army. He coincidentally discovered that during the collection of his data for his records, which consisted primarily of group discussions with troops, that these discussions influenced troops' emotions for the better (Mirzamani, 2006). This was known as Historical Group Debriefing (HGD) (Adler, Castro, \& McGurk, 2009). In the early 1980's Mitchell developed a model 
named critical incident stress management (CISM) for the emergency medical services in the United States of America (USA). Part of the CISM programme was a model called critical incident stress debriefing (CISD). A lot of attention has since been placed on this one aspect of CISM because it was believed that CISD can be used to prevent the development of PTSD.

Then, in 1989, a Norwegian psychologist by the name of Dyregrov adopted the term PD but maintained that PD and CISD were essentially the same thing. Ever since, the two terms have become interchangeable and serve the same meaning (Regel, 2007). The past couple of years different models on PD were developed. Following is a discussion of those models

\section{Mitchell's model}

Mitchell developed one of the first PD models in 1983. His original model consisted of a "comprehensive, systematic and integrated multi-component crises intervention package" (Regel, 2007, p.411). This package was developed for the use of individual as well as group interventions. This model was known as the CISM model (Regel, 2007). The CISM model comprised of many elements including pre-crisis education, assessment, defusing, CISD and specialist follow up (Regel, 2007).

For the purpose of this paper, only CISD will be discussed as it is the element that has received the most focus during the past few years. CISD is a structured approach that consists of seven phases. These phases include the following: 1) the introductory phase, 2) the fact phase, 3) the thoughts phase, 4) the reaction phase, 5) the symptom assessment phase, 6) the information phase and 7) the re-entry phase (Devilly, \& Cotton, 2003).

During the introductory phase, the participants are introduced to the CISD model and its components. They are also informed that confidentiality applies to the entire session and that they should feel free to say whatever they want. It is also emphasised that they will not be forced to say more than they want to, but they are encouraged to participate in the discussions. One of the most important parts of the introduction is to make it clear to the participants that PD is not counselling or psychotherapy, but a discussion of psychological elements (Mirzamani, 2006). During the fact phase, the aim is to establish the facts of the particular incident. This is done by asking specific questions, for example, 'Where were you deployed?' and 'What happened when you made contact with the enemy?' During this stage their emotions will also come to the fore. These emotions are openly acknowledged and judged as normal reactions to the traumatic event (Rose, \& Tehrani, 2002).

During the third phase, the participants' initial thoughts regarding the event are discussed. Here participants are encouraged to discuss the personal meaning the event has for them (Rose, \& Tehrani, 2002).

During the fourth phase, which is the reaction phase, the participants discuss the emotional, physical and behavioural reactions that result from the traumatic event. This phase usually takes the majority of the session and is the deepest phase of the PD session. The facilitator will ask questions such as 'What is the worst part of this event for you?' During this phase, participants are urged to speak freely and openly about their fears and emotions associated with the event. The fifth phase is the symptom assessment phase. During this phase the facilitator will look for physical, emotional, cognitive or behavioural symptoms of PTSD and other psychological disorders associated with traumatic events (Mirzamani, 2006). 
The next phase of the intervention is the information and teaching phase. During this phase general information is given regarding the stress reaction and the normal nature of these reactions. The facilitator gives specific advice regarding the reactions the individuals can expect as a result of the stressor (Mirzamani, 2006).

The facilitator also gives the participants advice regarding alcohol consumption, relationships and other relevant factors (Rose, \& Tehrani, 2002). The last phase of this model consists of the re-entry phase. During this phase, all the issues that were discussed are summarised and further attention is given to certain issues if needed (Mirzamani, 2006). It is also during this phase that referral information is provided for future follow ups (Devilly, \& Cotton, 2003). Individuals who show symptoms of PTSD or other psychological disorders associated with trauma must be refered to qualified professionals so that they can receive help as soon as possible (Rose, \& Tehrani, 2002).

\section{Dyregrov's model}

Dyregrov based his PD model on the work of Mitchell, although there are some differences between the two models (Mirzamani, 2006). For the purpose of this paper, only the differences will be discussed seeing that the models are relatively similar. There are three main differences between the two models. Firstly, where Mitchell's model starts the discussion with where the traumatic event started, Dyregrov starts his discussion of the event at what happened before the event occurred. He does this by asking questions such as 'How did you find out about this event?' (Rose, \& Tehrani, 2002).Secondly, Dyregrov also focused on the cognitive decision making process of the individual during the event. This is done by asking questions such as 'Why did you decide to do that?' It is suggested that these questions reduce the tendency of individuals to blame themselves for what has happened. A third difference between the two models is that Dyregrov also focused on sensory information by asking questions such as 'What did you hear, smell, taste and see?' Dyregrov's model placed more emphasis on the reaction and responses of the individuals than Mitchell's model does and it is therefore suggested to be safer for the participants (Rose, \& Tehrani, 2002).

The controversy on PD as illustrated by Van Wyk and Edwards (2005) is that "debriefing" is a military term referring to interviews in which critical incidents are examined by those involved in them and those in authority. Everly and Mitchell (2000) wrote critical incident stress debriefing (CISD) refers to one form or model of group crisis intervention, sometimes generally referred to as group psychological debriefing (PD). CiGrang, Peterson and Schobity (2005) wrote that there are a number of factors that have made PD especially appealing to a military population. PD deemphasizes psychotherapy and pathology, while emphasising normalization of reactions and returning members of the military to duty. The authors are aware of the academic discussion on the advantages and disadvantages of PD, but this is not the focus of this article.

The authors want to use the advantages of PD, but agree with Edwards, Sakasa and Van Wyk (2005), Petronko (2005) and Nathan (2005) that a once off PD session is not the most effective method to deal with PTSD. PD will be part of the proposed model with the function that members can get psychological closure after a traumatic event. Further it can be used as a psychological triage by clinical psychologists on members who are psychologically fit to go back to the operational environment (Dhladhla \& Van Dyk, 2009). 


\section{Raphael's model}

Raphael starts the debriefing process by focusing on factors prior to the traumatic event. However, her focus was more on the training and preparation the individuals received prior to the incident. Her model also suggested some areas that may be useful during the intervention. According to Rose and Tehrani (2002), these include the following:

- The stressors that the person experiences personally, such as death and survivor conflict.

- Frustrations that may increase the stressors. For example, inadequate skills, training or equipment that could have helped prevent the incident.

- Special relationships with friends and colleagues who experienced the same incident.

It is suggested that these topics are discussed in a systematic manner to ensure that the participants can work through the emotions that may be evoked. Raphael's model makes use of more straight forward questions such as 'Was your life directly in danger?' This model also focuses on positive aspects of the incident by asking questions such as 'Do you feel good about something you did?' Raphael also suggested that the participants analyse the feelings of people who went through the same incident. These aspects are not present in the previous two models (Rose, \& Tehrani, 2002).

Lastly, the model focused on what was learnt from the experience of the incident, feelings around going back to duty and the problems that can arise from returning to the battlefield (Rose, \& Tehrani, 2002).

\section{The multiple stressor debriefing model}

According to Mirzamani (2006), the multiple stressor debriefing (MSD) model consists of four stages. During the first stage, the participants are introduced to debriefing and ground rules are laid down for the duration of the intervention. The participants are then asked to describe what it is about the incident that troubles them the most.

During the second phase of this model, participants are asked to describe their feelings and reactions they experienced as a result of the incident. The third phase of this model emphasised the coping strategies that the participants will need and they are also given information regarding normal and abnormal reactions to stress. Participants are asked about their previous coping skills in the past as well as how they are coping with the current stress. The facilitator will use coping strategies identified within the group and where possible not introduce new strategies. During the last stage of this model, the participants are asked to give their views on how they feel about leaving the disaster site. The emphasis of the discussion then moves to separating from coworkers and preparing them to terminate the PD session. Before leaving, it is emphasised that the participants must continue talking with their colleagues and their partners. By the time they leave, any remaining questions are answered and referrals are made if necessary (Mirzamani, 2006).

\section{Frontline treatment}

Frontline treatment has been used for many years in different militaries around the world. It is considered that the closer to the frontlines individuals are debriefed the quicker they will return 
to active duty. It has been suggested that soldiers must only be removed from the battlefield if there is no improvement in their abnormal behaviour (Freedy, \& Hobfoll, 1995).

The intervention of trauma usually starts by providing the soldier with temporary relief from stress and seeing to his/her biological and social needs (Freedy, \& Hobfoll, 1995). This model is based on the principles of proximity, immediacy and expectancy where the expectancy is that soldiers will return to active duty as soon as possible. According to Freedy and Hobfoll (1995), this model follows the following guidelines:

- Meet the individuals' physiological needs first.

- Treat the individuals as soon as possible.

- Temporary relief from the stressor is provided.

- Use human contact to reassure, clarify and share emotions.

- Humanise and legitimise fears.

- Allow expressions of grief, guilt and shame, but challenge self-depreciation.

- Convey to the individual expectation of full recovery and return to duty.

- Promote social support that will allow reintegration of the casualty in his/her unit.

- Do not change the soldier's status as a member of the combat team until appropriate efforts to reverse the traumatic effects of the stress have been made and have been proven unsuccessful.

It is important to prevent isolation during the first stages of the treatment as this may worsen the traumatic experience. Based on the three principles of this model, proximity, immediacy and expectancy, it is suggested that the individual is treated as close as possible to the battlefield as soon as possible, with the expectation that he will return to the battlefield. This is the bases of the model and is believed to contribute to the success of PD (Freedy, \& Hobfoll, 1995).

\section{Battlemind psychological debirefing}

Battlemind Psychological Debriefing is one of the newest models of PD. According to Adler et al. (2009), three types of Battlemind Psychological Debriefing have been developed. Two of these are 'in-theatre' models and the third one occurs at post deployment.

For the purpose of this paper, only the in-theatre models will be discussed. These two models are namely the 'Time-Driven Battlemind Psychological Debriefing' and the 'Event-Driven Battlemind Psychological Debriefing'. Time-Driven Battlemind Psychological Debriefing is designed to be implemented at intervals during deployment whereas Event-Driven Battlemind Psychological Debriefing has been designed to be implemented when support is requested after a traumatic event. Due to the fact that units may be deployed in remote areas for long periods of time, it is not always possible to provide them immediately with professionals to facilitate PD when such a request is made. For this reason, Time-Driven Battlemind Psychological Debriefing is favoured above Event-Driven Battlemind Psychological Debriefing. 
The Time-Driven Battlemind Psychological Debriefing model consists of 5 phases which includes the 1) introduction phase, 2) event phase, 3) reactions phase, 4) self and buddy-aid phase and 5) the battlemind focus phase. During the introduction phase, the facilitator briefly gives the participants some information about him/herself and his/her experience. He then introduces the program and its aims and gives positive expectations for the program. During this phase the ground rules for the session are also laid down. It is important for the facilitator to make it clear to the participants that they will have to return to duty after the session is complete. During the second phase, the events phase, the facilitator establishes the events that have placed the unit under strain. The facilitator asks the members to discuss one or two specific events that may have happened during the deployment that may be difficult for them to think about. The facilitator must gather as much information about the incident from the group as possible, but must not allow the group to get over-involved on one point (Adler et al., 2009).

The goal of the next phase, the reaction phase, is to have the participants share their reactions in order to normalise their reactions. This phase commences by focusing on the cognitive responses of the members and continues on to their emotional responses. Before the facilitator transitions to the next phase, he/she must summarise what was said and include reactions that may occur that might have been left out by the members. It is also important for the facilitator to address issues of self blame and doubt that the members might have regarding their actions. The fourth phase focuses on the identification of three major symptoms: anger, withdrawal and sleep problems. The goal is to normalise these symptoms and explain to the soldiers what they can do for themselves as well as their buddies. During the discussion of anger, it is important to explain to the participants that it is normal to develop a short temper and that feelings of revenge are normal, but it must be emphasised that they need to remain professional and be able to return home with a story that they "can live with". When discussing withdrawal, it is important for the members to discuss the signs of withdrawal as well as the importance of keeping an eye on each other to ensure that a fellow member receives the necessary support and professional help when needed (Adler et al., 2009).

Lastly, when discussing the problems, it is important for the facilitator to once again normalise sleep problems and discuss solutions for sleep disturbances. The last phase of this model focuses on helping the group become psychologically ready to continue with their deployment (Adler et al., 2009).

Facilitators ask questions to extract ways in which members have maintained perspective, focused on positive adaptation, identified coping strategies and recognised similarities and differences in their adjustment. This is done in order for participants to learn how to cope with the stressor through sharing it with each other. Participants must be reminded that they must 1) trust their military training and personal decisions, 2) watch out for one another 3) listen to their leaders and 4) inform their leaders if there are any problems. In closing, the facilitator should inform participants where they can receive further help if they should need it, and must emphasise that seeking help when in need of it is a sign of strength and leadership (Adler et al., 2009).

\section{Proposed PD model for military forces in Africa}

It has been suggested that high-risk organisations such as the military and police force should make use of models that do not only include an intervention model, but other tactics and strategies as well. One such model is the CISM model which consists of the following methods, in addition to CISD (Everly, \& Mitchell, 1999, pp. 71-92):

TD, 6(2), December 2010, pp. $379-394$. 
- Pre-incident preparedness training: This refers to educating soldiers in high-risk occupations about the kinds of stressors they are likely to encounter on the job, about common stress reactions and about stress-management techniques. This can be given to soldiers prior to deployment so that they can know what to expect.

- One-on-one individual crisis support: This refers to attempts to mitigate acute stress reactions, often at the scene of the trauma. The counsellor attempts to provide psychological distance between the scene and the soldier in distress by having the person take a walk or withdraw for a couple of hours from the battle field. This may not always be possible immediately during military operations, but necessary when possible.

- Demobilisation: This refers to providing food, rest and information about coping with stress reactions to large groups of soldiers as they rotate off duty. This method includes group informational briefing, which refers to providing facts about a critical incident to a large group of individuals indirectly affected, as well as providing information about common psychological dynamics (e.g. grief, anger) and about how to access psychological services. These tactics are only relevant to the military in terms of providing food and rest to the individual for a couple of hours.

- Debriefing: This refers to a small-group intervention that usually takes place within twelve hours of the traumatic event. It involves having participants explore and discuss the incident and their emotional reactions to it. It is the practise in the Canadian Defence Force (Rosebush, 1998) and in the armed forces of the United States of America (Keller, 2005) to sensitise and empower military leaders with knowledge of PD for the management and early referral of soldiers in operations.

- Family support: This refers to debriefing family members of the soldiers involved in the crisis. For example, giving support to spouses of soldiers in the military.

- Referral mechanisms: This is concerned with procedures for referring individuals for psychiatric or psychological services. The facilitator must provide the individuals with information on where and how to get help from trained specialists if needed.

If a model such as CISM is considered for the military forces in Africa then certain limitations may arise, such as problems with regards to having enough debriefers available to implement the program as needed. A possible solution to this problem would be to train platoon commanders and company commanders to be able to do PD in their platoons or companies as needed. This can be the first line of defence against the development of psychological problems. However, this would mean that they would also have to be trained to recognise the signs and symptoms of PTSD, CSR and ASR so that the affected individual can be referred to the field hospital when needed.

Another solution will be to train medics in PD so that the medic in the combat situation is not only trained to treat physical injuries, but also to prevent psychological disorders.

\section{Proposed model for traumatised communities in Africa}

The models above are more applied in the military which is a more structured environment than rural communities in Africa. On the other side, there is also a need to apply a debriefing model for communities in Africa for example in Mozimbique (flood), Ethiopia (drought), Kenya (political unrest), Uganda (bomb blast) and Zimbabwe (political unrest). It is important to be 
aware of some of the specific characteristics of African communities in the management of PD. Sefotho (2005) wrote that psychological services, to do debriefing is not common practice in the communities in Africa. On the other hand there is high levels of trauma in the African rural communities around HIV/AIDS (Bakunda, 2009), annual victims of abortions (Temu, 2006), single parenthood and HIV/AIDS orphans (Nakkazi, 2008). A high percentage of the population have low levels of education and a limited mental health service to support them with trauma or psychological debriefing.

This paper wants to propose out of the above models of PD a simple model for African communities which will be suitable for people with a low education level, possible to implement without modern infrastructure and be applicable with simple resources - specifically for children.

Van Dyk (1999) developed an adjusted model for Africa, consisting out of three phases:

Cognitive phase, where people can tell their story in terms of what they saw, heard and experienced in a group of ten people, in a half circle.

Affective phase, this is where people start to vent/share their deepest, most painful and traumatic experiences and specific emotions. It is where people work through feelings of guilt, fear, resentment and anger. African communities, with a more collectivistic approach, are doing better in a group situation where they feel together, cry together and support each other.During this phase the following techniques are available to help children (Van Dyk, 2000):

- Telephone game - children phone a family member to tell their story and share their emotions.

- Sunglasses - children hide behind dark glasses when sharing their emotions.

- Puppet play - children use puppets to project their emotions to the puppets.

Empowerment phase, here the debriefer use the potential and creativity of the group to facilitate solutions for their helpless and powerless situations. Doing so to create a future and to empower their ego power. It is important to use games, play and role modelling to empower the children of Africa.

Psychologists can train teachers, nurses, sisters, and community leaders to become debriefers in the African communities for the better mental health of our people.

\section{Summary and concluding remarks}

PD has evolved a lot since World War I, but the aim and ways of implementation of PD has mostly stayed the same. There are a number of different models of PD, but they all essentially have the same structure and only differ in terms of their focus. The proposed PD model for the military forces in Africa can hopefully be helpful in preventing PTSD as well as to facilitate a higher level of mental health in soldiers.

The model for the traumatised communities in Africa can be implemented through hospitals, schools, as well as the ministers of health and education in Africa. It is believed that the implementation of these models can potentially bring relief to the traumatised people in Africa. 


\section{References}

Adler, A.B., Castro, C.A., \& McGurk, D. (2009). Time-Driven Battlemind Psychological Debriefing: A Group-Level Early Intervention in Combat. Military Medicine, 174, 21 28.

American Psychiatric Association (APA). (2005). Let's Talk Facts About Posttraumatic Stress Disorder. Arlington: APA.

Arendt, M., \& Elklit, A. (2001). Effectiveness of Psychological Debriefing. Acta Psychiatrica Scandinavica, 104, 423-437.

Bakunda, A.J.K. (2009). Psychological Trauma, Caring Strategies and Resilience of Children Living with HIVIAIDS. Unpublished Masters Thesis, Makerere University, Makerere.

Baumann, S.E. (1998). Psychiatry and Primary Health Care: A Practical Guide for Health Care Workers in South Africa. Cape Town: Zebra Publications.

Bisson, J. I., McFarlane, A. C., \& Rose, S. (2000). Psychological Debriefing. In E. B. Foa, T. M. Keane, \& M. J. Freidman (Eds.), Effective treatment for PTSD (pp. 39-59). New York: Guilford Press.

Bruwer, N., \& Van Dyk, G.A.J. (2005). The South African Peacekeeping Experience:

Comparative Analysis. South African Journal of Industrial Psychology, 31(2), 30-39.

Bryant, R.A., \& Harvey, A.G., (2002). Acute Stress Disorder: A Handbook of Theory, Assessment and Treatment. Washington, DC: American Psychological Association.

Carll, E.K., (2007). Trauma Psychology. Issues in Violence, Disaster, Health and Illness. Westport: Praeger Publishers.

CiGrang, J.A., Peterson, A.L. \& Schobity. (2005). Three American Troops in Iraq: Evaluation of a Brief Exposure Therapy Treatment for the Secondary Prevention of Combat Related PTSD. Pragmatic Case Studies in Psychotherapy. Vol 1, Module 2, Article 1, pp 1-25.

Crocq, L. \& Crocq, M.A., (1987). Trauma and Personality in the Causation of War Neuroses. In Belenky, G. (Ed.), Contemporary Studies in Combat Psychiatry (pp 103-116). Westport: Greenwood Press

Deahl, M., (2000). Psychological Debriefing: Controversy and Challenges. Australian and New Zealand Journal Of Psychiatry, 34, 929-939.

Devilly, G.J., \& Cotton, P. (2003). Psychological Debriefing and the Workplace: Defining a Concept, Controversies and Guidelines for Interventions. Australian Psychologist, 38, 144150 .

Dhladhla, T.J. (2008). Demobilisation and Reintegration of Ex-Combatants into Civilian Life: Healing the wounds? In G.A.J. Van Dyk (Ed.), Strategic Challenges for African Armed Forces for the Next Decade (pp 65 - 83). Stellenbosch: Sun Media. 
Dhladhla, T.J, \& Van Dyk, G.A.J. (2009). Management of Post-Traumatic Stress Disorder in the Military: An Intervention Model. Journal of Psychology in Africa, 19(4), 591-596. Devilly, G.J., Gist, R., \& Cotton, P. (2006). Ready! Fire! Aim! The Status of Psychological Debriefing and Therapeutic Interventions: In the Work Place After Distress. Review of General Psychology, 10(4), 318-345.

Dyregrov, A. (1997). The Process in Psychological Debriefings. Journal of Theraputic Stress, 10(4), 589-605.

Edwards, D., Sakasa, P. \& Van Wyk, G. (2005). Trauma, Resilience and Vulnerability to PTSD: A review and clinical case analysis. Journal of Psychology in Africa, 15(2), 143153.

Everly, G.S., Jr., \& Mitchell, J.T. (1999). Critical Incident Stress Management (CISM): A new era and standard of care in crisis intervention (2nd ed.). Ellicott City, MD: Chevron.

Everly, G.S. \& Mitchell, J.T. (2000). The Debriefing "Controversy" and Crisis Intervention: A Review of Lexical and Substantive Issues. International Journal of Emergency Mental Health, 2(4), 211-225.

Foy, D.W., Erikson, C.B., \& Trice, G.A., (2001) Introduction to Group Interventions for Trauma Survivors. Group Dynamics Theory, Research and Practice, 5(4), 246-251.

Freedy, J.R., \& Hobfoll, S.E., (1995). Traumatic Stress: From Theory to Practice. New York: Plenum Press.

Human Development Report. (2005). UN Development Programme, Brussels, UN.

Keller, T. (2005). Soldier Peer Mentoring Care and Support: Bringing psychological awareness to the front. Military Medicine, 17(1), 355-363.

Lewis, S.J., (2001). Do One-Shot Preventive Interventions for PTSD Work? A Systematic Research Synthesis of Psychological Debriefings. Aggression and Violent Behaviour, 8, 329343.

McNally, R.J., Bryant, R.A., \& Ehlers, A., (2003). Does Early Psychological Intervention Promote Recovery from Posttraumatic Stress? Psychological Science in the Public Interest, 4(2), 45-79.

Mirzamani, S.M., (2006). PTSD and Psychological Debriefing. Iranian J Psychiatry, 1(3), 88-92.

Nakkazi, H. (2008). Sickle Bell Disease, Family Functioning and Psychological Well-Being among Uganda Adolescents. Unpublished Masters Thesis, Makerere University, Makerere.

Nathan, P.E. (2005). Bringing Home the Psychological Immediacy of the Iraqi Battlefield. Pragmatic Case Studies in Psychotherapy. Vol 1, Module 2, Article 2, pp 1-3. 
Noy, S., (1987). Stress and Personality as Factors in the Causation and Prognosis of Combat Reaction. In Belenky, G. (Ed.), Contemporary Studies in Combat Psychiatry (pp 21-29). Westport: Greenwood Press

Perry, B., (2006). Effects of Traumatic Events on Children. Retrieved February 15, 2009, from http://www.childtrauma.org/ctamaterials/interdis.asp

Petronko, M.R. (2005). Towards Formalizing a Very Promising Treatment. Pragmatic Case Studies in Psychotherapy. Vol 1, Module 2, Article 3, pp 1-6.

Regel, S., (2007). Post-trauma Support in the Workplace: The Current Status and Practice of Critical Incident Stress Management (CISM) and Psychological Debriefing (PD) within Organisations in the UK. Occupational Medicine, 57, 411-416.

Rose, S., \& Tehrani, N. (2002). History, Methods and Development of Psychological Debriefing. In The British Psychological Society (BPS) (Ed.), Psychological Debriefing (pp. 2-7). Leicester: BPS.

Rosebush, P.A. (1998). Psychological Intervention with Military Personnel in Rwanda. Military Medicine, 168(8), 559-563.

Sefotho, M.M. (2005). Psychotherapy and Educational Career Counselling. In S.M. Madu and S. Govender (Eds). Mental Health and Psychotherapy in Africa (pp146-164). Polokwane: University of Limpopo Press.

Temu, S.M.D. (2006). Married Women's Knowledge and Attitudes Towards Contraceptive use and Psychological Well-Being in Three Rural Villages in Kilimanjaro, Tanzania. Unpublished Masters Thesis, Makerere University, Makerere.

The Coalition to Stop the Use of Child Soldiers. (2008). Child Soldiers Global Report. Geneva: Quaker United Nations Office.

The UN Refugee Agency. (2007). Statistical Yearbook. Geneva: UNHCR.

UNAIDS. (2007). AIDS Epidemic Update. Geneva: UNAIDS.

Van Dyk G.A.J. (2000). Psychological debriefing: an adjusted model for community workers to heal traumatised children in South Africa. In N. de Meillon, Creative Rescue Counselling and Assistance for the children in our country. Pretoria: UNISA

Van Dyk, G.A.J. (1999). Psychological Trauma Debriefing as a Therapeutical Tool in the treatment of victims of political or ethnic violence in Africa. In S.M. Madu, P.K.

Baguma, \& A. Prity (Eds.) Cross Cultural Dialogue on Psychotherapy in Africa (pp. 69-86). Pietersburg: University of the North.

Van Wyk, G. \& Edwards, D. (2005). From trauma debriefing to trauma support. A South African experience of responding to individuals and communities in the aftermath of traumatising events. Journal of Psychology in Africa, 152, 135- 142. 